\title{
ECONOMIC EVALUATION OF SMALL CAPACITY SEWAGE PROCESSING UNITS
}

\section{M.K. GRATZIOU* \\ M. TSALKATIDOU N.E. KOTSOVINOS}

Selected from papers presented in $9^{\text {th }}$ International Conference on Environmental Science and Technology (9CEST2005) 1-3 Septmber 2005, Rhodes island, Greece
Department of Civil Engineering

Democritus University of Thrace

Vas. Sofias 12, 67100, Xanthi, Greece

*to whom all correspondence should be addressed e-mail: mgratzi@civil.duth.gr

\begin{abstract}
This paper aims at a comparative evaluation of the total cost of urban sewage processing units for several treatment systems, appropriate mainly for small capacity plants. The studied systems are: Oxidation Ditch (O.D.), Trickling Filter (T.F.), Rotating Biological Contactor (R.B.C.), Compact Sequential Batch Reactor (S.B.R.), Waste Stabilization Ponds (S.P.) and Subsurface Constructed Wetland Systems (C.W).

For each system, operation and construction costs are calculated as a unit capacity function for a 40-year operating period. Cost calculation is based on the analysis of its several components such as energy consumption, chemicals consumption, personnel salaries, maintenance expenses, construction materials and their respective quantities, required mechanical equipment and land value. All pecuniary flows, in order to be comparable are converted into current value.
\end{abstract}

Cost estimation is based, mainly, on the calculation of the several cost elements' quantities, with the development of standardized plans. Total and partial costs are expressed as functions of plant capacity. The annual operation and maintenance (O\&M) cost, the project cost, as well as the total construction, maintenance and operation cost for 40 years of operation (Present Value) can be written as a function of flow rate, in the form of $a+b Q+c Q^{2}$; whereas energy cost can be described by a linear function of flow rate, in the form of $a+b Q$, with excellent approximation. The coefficients $a, b, c$, for the various treatment methods examined and for every cost category are summarized in tables.

All treatment methods exhibited positive scale economies for the studied region of cost per E.P.; this trend was especially evident for plant capacities up to 5,000 E.P.

Natural wastewater treatment methods present the least expensive option for the examined range of E.P. The classification of the treatment methods from the least to the most expensive one depends on plant capacity. The classification of the treatment methods based on their cost for different plant capacities is provided.

The results provide a first level of information, which could be utilized for a quick financial evaluation of the aforementioned systems as well as in the general decision making plan.

KEYWORDS: Cost, Wastewater Treatment plant, Urban Sewage.

\section{INTRODUCTION}

This paper aims at a comparative evaluation of the total cost of relatively small capacity urban wastewater treatment plants. The equivalent population ranges from 100 up to 20,000 . The following wastewater treatment systems are studied: Oxidation Ditch (O.D.), Trickling Filter (T.F.), Rotating Biological Contactor (R.B.C.), Compact Sequential Batch Reactor (S.B.R.), Waste Stabilization Ponds (S.P.) and Subsurface Constructed Wetland Systems (C.W). 
All methods include a preliminary treatment stage, drying beds are used for sludge dewatering while chlorination is chosen for disinfection. When sludge dewatering is achieved through the usage of band filter press, cost increases by approximately $40 \%$ [1]. Only in the case of the waste stabilization ponds, a different disinfection method is preferred. The ponds system consists of an anaerobic, a facultative and two maturation ponds in series. An Imhoff tank is used for primary treatment in the constructed wetlands. For the constructed wetland system we also study the alternative scenario of using a maturation pond to achieve disinfection.

For the cost to be calculated, it is divided into its components, such as energy consumption, chemicals' consumption, personnel salaries, maintenance costs, construction materials and their respective quantities, mechanical equipment, land cost, amortizations. All pecuniary flows, in order to be comparable, are converted into current value taking an $8 \%$ interest rate for a 40-year timescale. For the calculations, typical costs in Greece are considered. For each case, scale economy and the functions of total cost (present value), project cost and O\&M cost, in relation to unit capacity, are estimated along with the annual energy cost functions.

The information offers a first detailed level for general planning and suggests a technique for quick financial evaluation of the treatment systems. The aim of evaluating expenses in pollution control is the minimization of the expenses required in order to meet a certain water quality target. This procedure is based on the rationale that the lower wastewater treatment system cost still has to meet the legal specifications for water quality instead of actually dictating them and should not be mixed with economic optimization terms that refer to maximization of the production yield and minimization of the cost. Therefore all designed units can treat with the same efficiency sewage of the same qualitative and quantitative characteristics.

\section{DESCRIPTION OF WASTEWATER AND SYSTEMS' CHARACTERISTICS}

All the designed units are assumed to treat sewage of the same qualitative and quantitative characteristics with equal efficiency. For the performed calculations the input wastewater is assumed to have the characteristics shown in Table 1.

The soluble BOD 5 and TSS of the wastewater output are assumed as $10 \mathrm{mg} \mathrm{l}^{-1}$ and $30 \mathrm{mg} \mathrm{l}^{-1}$ respectively. The qualitative characteristics of the sewage output are in accordance with the European Community's Urban Wastewater Treatment Directive (EEC 91/271) [2].

Preliminary treatment includes screening and grid removal. The sewage is mechanically cleaned at $30 \mathrm{~cm}$ depth thereupon is aerated. For the grid removal two units are used, detention time is $2.5 \mathrm{~min}$ and at a depth equal to $1.25 \mathrm{~m}$.

For sludge dewatering drying beds are used, with drain time lasting 2 days. The percentage of the drained solids is $20 \%$, while final solids are $50 \%$. The evaporation rate is assumed to be $127 \mathrm{~mm} \mathrm{month}^{-1}$ and rainfall is considered as $76 \mathrm{~mm}$ per month. The absorbed fraction is 0.57 .

For chlorination detention time is $30 \mathrm{~min}$ while the chlorine dose is $10 \mathrm{mg} \mathrm{I}^{-1}$.

The operational characteristics of the Oxidation Ditch are assumed as follows: MLSS concentration $6000 \mathrm{mg} \mathrm{I}^{-1}$, volatile fraction 0.75 and the $\mathrm{F} / \mathrm{M}$ ratio $0.065 \mathrm{kgBOD} / \mathrm{kgVSS}$.

All steel pipes and mechanical equipment are assumed to be replaced every 20 years; the chlorinator is replaced every 15 years and pumps after 10 years. Structural elements are replaced every 40 years therefore for the studied 40 -timespan no replacement of the latter is considered.

Table 1. Wastewater input characteristics

\begin{tabular}{lll}
\hline & Wastewater input characteristics \\
\hline TSS: $220 \mathrm{mg} \mathrm{I}^{-1}$ & COD: $500 \mathrm{mg} \mathrm{I}^{-1}$ & $\mathrm{NH}_{3}: 25 \mathrm{mg} \mathrm{I}^{-1}$ \\
$\%$ VS: $75 \%$ & Sol. COD: $300 \mathrm{mg} \mathrm{I}^{-1}$ & $\mathrm{pH}: 7.6$ \\
BOD $_{5}: 220 \mathrm{mg} \mathrm{I}^{-1}$ & TKN: $40 \mathrm{mg} \mathrm{I} \mathrm{I}^{-1}$ & Cations: $160 \mathrm{mg} \mathrm{l}^{-1}$ \\
Sol. BOD $: 80 \mathrm{mg} \mathrm{I}^{-1}$ & TP: $8 \mathrm{mg} \mathrm{I}^{-1}$ & Anions: $160 \mathrm{mg} \mathrm{I}^{-1}$ \\
Settleable Solids: $10 \mathrm{ml} \mathrm{I}^{-1}$ & & Non Degradable Fraction of VSS: $40 \%$ \\
Average Summer Temperature: $23^{\circ} \mathrm{C}$ & Average Winter Temperature: $10^{\circ} \mathrm{C}$ \\
\hline
\end{tabular}




\section{METHODOLOGY- CALCULATIONS}

Cost estimation is based on the identification of its elements which are then cost accounted. The calculation of the several elements quantities was achieved with the development of standardized plans for various flows and a change in supply. In the approach of real data expenses, construction details are determined clearly enough for an adequate calculation of the elements required for cost estimation such as material quantities, working man-hours etc

\subsection{Calculating Quantities and Construction Expenses}

The most important building expenses for the construction of any treatment unit can be classified as follows:

- Tanks and other concrete or steel constructions.

- Installed equipment.

- Building and housing.

- Channeling with pipes, insulation and support.

- Electrical work, control systems and other installations.

According to Andreadakis and Chalkia (1992) the first four elements can be precisely evaluated and they generally account for $85 \%$ of the total main expenses [3]. The cost of the remaining elements can be calculated as a percentage of the total expense, e.g. electrical equipment in a wastewater treatment plant depends greatly on its mechanical equipment. The estimated electrical expenses are incorporated as a percentage in the mechanical equipment expenses, the latter involving the purchasing equipment cost, the installation cost and other secondary expenses. The purchasing cost of the mechanical equipment is a function of size or capacity [4]. The man-hours required for the installation depend on the type and size of equipment to be installed. Data related to the workforce required for equipment installation are either inadequate or non-existent, therefore a percentage of the purchasing factor is used to estimate the equipment installation cost. Building demands depend on the housed equipment and are calculated as quantities (i.e. square meters).

The construction of wastewater treatment plants depends not only on the construction of the processing units, but also on the completion of the supporting plant and piping network, in order for the whole unit to be operational. These construction expenses of the processing units are found to represent $35 \%$ to $50 \%$ of the total construction cost; piping expenses range between $15 \%-20 \%$ [5].

Other important construction costs include the contractors' profit and contingent expenses. Since these costs are calculated based on the total construction cost, net procedure expenses are multiplied by a percentage that defines a value for contractors' profit and contingent expenses. In Greece the enacted contractor's profit percentage amounts to $18 \%$ while contingent expenses to $15 \%$. Total construction expenses are calculated as the sum of processing units' expenses, other construction expenses (service networks, surrounding area etc), contractors' profit and contingent expenses [6].

The calculation of the project cost includes not only construction cost but also non construction expenses related to planning, design and land cost. Non construction expenses are expressed as a percentage of the total construction expenses, e.g. $2 \%$ for legal expenses, $15 \%$ for the study fee, $3.5 \%$ for planning etc. Land cost is assumed as $1500 €$ per $1000 \mathrm{~m}^{2}$.

\subsection{Calculating Operation and Maintenance Cost}

The analysis of the operation and maintenance expenses includes:

- Personnel salaries, labor wages for maintenance and operation.

- Necessary operating electrical energy.

- Material required for repairs.

- Chemical substances and other demands.

- Replacement program.

The personnel required for each treatment unit depends on its size. The total man-hours requirements and the salaries expenses are also related to plant size. The administrative working group includes management and office personnel. The laboratory group consists of personnel required to run the necessary tests, to check the several parameters that ensure an effective treatment. The total man-hours requirement for these groups is related to the plant 
size: Man-hours $=f\left(Q_{a v g}\right)$. The requirement for the first group is calculated using the following equation:

$$
\Delta \mathrm{A}=0.55\left(\mathrm{Q}_{\mathrm{avg}}\right){ }^{0.7829}
$$

Where $\Delta \mathrm{A}$ (man-hours $\left.\mathrm{yr}^{-1}\right)$ and $\mathrm{Q}_{\mathrm{avg}}\left(\mathrm{m}^{3} \mathrm{~d}^{-1}\right)$ are the administrative man-hours required and the average wastewater flow rate respectively.

The man-hours requirement for the second group, with $150 \leq Q \leq 30,000 \mathrm{~m}^{3} / \mathrm{d}$, is calculated using the equation below:

$$
\mathrm{EA}=703.1\left(\mathrm{Q}_{\mathrm{avg}}\right)^{0.1515}
$$

Where EA (man-hours $\mathrm{yr}^{-1}$ ) and $\mathrm{Q}_{\mathrm{avg}}\left(\mathrm{m}^{3} \mathrm{~d}^{-1}\right)$ are the laboratory man-hours required and the average wastewater flow rate respectively [7].

In order for the man-hours to be converted into expenses, they are switched into working personnel and multiplied to an average annual salary for every working group.

The quantities of each chemical required for the treatment processes are calculated at the first stage of the quantities calculation. The chemicals' expenses are given by the following general equation:

$\sum E K i=\sum$ (cost of chemical substance i)(daily requirement of substance i)365

Where EKi $\left(€ \mathrm{yr}^{-1}\right)$ is the annual cost of the chemical substance i.

The electrical energy consumed for the treatment is the total sum of the energy consumed in each stage of the process. The annual energy cost is calculated by multiplying the annual energy consumption (KWh) to the cost of KWh (i.e. $8 €$ ).

Replacement cost is applicable on all those construction elements which have a lifespan shorter in duration than the planning period and therefore need to be replaced during the latter. Replacement cost is assumed to be equal to the initial cost of those elements.

\subsection{Calculating Present Value}

Total Present Value is the sum of the Present Values of all Partial Costs.

For the calculation of Present Value, land cost is not considered since we assume that the present salvage land value is equal to its current value. Inflation was also not considered as it was assumed that the general inflation percentage influences rather similarly all the alternative solutions.

\section{RESULTS}

\subsection{Cost functions}

Total Cost (Present value) and Project Cost can be estimated as a function of flow rate $Q$, in the form of $a+b Q-c Q^{2}$ or alternatively in the form of $a+b Q$; the annual Operation and Maintenance cost (O\&M) can also be expressed in terms of flow rate, in the form of $a+b Q$ $c Q^{2}$, whereas Energy Cost can be described by a linear function of flow rate in the form of a + $\mathrm{bQ}$. These functions are all excellent approximations and applicable to the majority of treatment systems. The coefficients $a, b, c$ for each studied system and for every cost category are presented in the tables below. Cost is expressed in $€$ and flow rate $Q$ in $\mathrm{m}^{3} \mathrm{~d}^{-1}$, with a range $15 \leq \mathrm{Q} \leq 30,000 \mathrm{~m}^{3} \mathrm{~d}^{-1}$.

Adjusted determination coefficients $\left(R^{2}\right)$ demonstrated excellent results, $R^{2} \geq 0.99$ in almost every case. Still $R^{2}$ is easily greater than 0.90 in every single examined scenario.

\subsection{Cost per equivalent population - Scale economies}

Table 5 presents the total cost per Equivalent Population for 40 years of plant operation of different treatment methods and for plant capacities of 100 E.P., 1000 E.P., 5,000 E.P., 10,000 E.P. and 20,000 E.P. Positive scale economies are observed; they are very strong for capacities up to 5,000 E.P., especially for conventional systems. 
Table 2. Coefficients $a, b, c$ of the total cost function, $K_{T}=a+b Q-c Q^{2}$

\begin{tabular}{lcccc}
\hline \multirow{2}{*}{ Process } & \multicolumn{3}{c}{ Coefficients } & \multirow{2}{*}{$\mathbf{R}^{2}$} \\
\cline { 2 - 4 } & $\mathbf{a}$ & $\mathbf{b}$ & $\mathbf{c}$ & \\
\hline Oxidation Ditch & $2 \times 10^{6}$ & 1773.7 & 0.1633 & 0.9925 \\
Trickling Filter & $2 \times 10^{6}$ & 1801.9 & 0.188 & 0.9945 \\
Rotating Biological Contactor & $1 \times 10^{6}$ & 2097.5 & 0.255 & 0.9915 \\
Compact Sequential Batch Reactor & 714,973 & 2113.9 & - & 0.9994 \\
Waste Stabilization Ponds & 759,259 & 1490.8 & 0.174 & 0.9947 \\
Constructed Wetlands-Lagoon & 511,466 & 1636.9 & - & 0.9981 \\
Constructed Wetlands-Chlorination & 793,000 & 1704.5 & - & 0.9965 \\
\hline
\end{tabular}

Table 3. Coefficients $a, b, c$ of the project cost function, $K_{p}=a+b Q-c Q^{2}$

\begin{tabular}{lcccc}
\hline \multirow{2}{*}{ Process } & \multicolumn{3}{c}{ Coefficients } & \multirow{2}{*}{$\mathbf{R}^{2}$} \\
\cline { 2 - 4 } & $\mathbf{a}$ & $\mathbf{b}$ & $\mathbf{C}$ & \\
\hline Oxidation Ditch & 805,023 & 1347.9 & 0.1315 & 0.9924 \\
Trickling Filter & 814,468 & 1485.9 & 0.1423 & 0.9967 \\
Rotating Biological Contactor & 598,940 & 1621.2 & 0.1883 & 0.9941 \\
Compact Sequential Batch Reactor & 101,566 & 1582.3 & - & 0.9993 \\
Waste Stabilization Ponds & 251,190 & 1202.7 & 0.1136 & 0.9976 \\
Constructed Wetlands-Lagoon & 101,566 & 1582.3 & - & 0.9993 \\
Constructed Wetlands-Chlorination & 277,105 & 1597.8 & - & 0.9987 \\
\hline
\end{tabular}

Table 4. Coefficients $a, b, c$ of the $O \& M$ cost function, $K_{p}=a+b Q-c Q^{2}$

\begin{tabular}{lcccc}
\hline \multirow{2}{*}{ Process } & \multicolumn{3}{c}{ Coefficients } & \multirow{2}{*}{$\mathbf{R}^{2}$} \\
\cline { 2 - 4 } & $\mathbf{a}$ & $\mathbf{b}$ & $\mathbf{C}$ & \\
\hline Oxidation Ditch & 48,123 & 44.105 & 0.0047 & 0.9929 \\
Trickling Filter & 47,020 & 30.288 & 0.0042 & 0.9866 \\
Rotating Biological Contactor & 42,550 & 30.080 & 0.0041 & 0.9923 \\
Compact Sequential Batch Reactor & 38,964 & 54,722 & 0.0038 & 0.9980 \\
Waste Stabilization Ponds & 27,167 & 21.010 & 0.0036 & 0.9797 \\
Constructed Wetlands-Lagoon & 30,544 & 17.089 & 0.0033 & 0.9489 \\
Constructed Wetlands-Chlorination & 38,887 & 22.591 & 0.0037 & 0.9750 \\
\hline
\end{tabular}

Table 5. Coefficients $a, b$ of the energy cost function, $K_{e}=a+b Q$

\begin{tabular}{|c|c|c|c|c|c|}
\hline \multirow{2}{*}{\multicolumn{2}{|c|}{ Process }} & \multicolumn{3}{|c|}{ Coefficients } & \multirow{2}{*}{$\mathbf{R}^{2}$} \\
\hline & & a & b & $c^{*}$ & \\
\hline \multirow{2}{*}{$\begin{array}{l}\text { Oxidation Ditch } \\
\text { Trickling Filter }\end{array}$} & & 10,372 & 12.830 & & 0.9999 \\
\hline & & 10,342 & 1.2646 & & 0.9942 \\
\hline \multirow{4}{*}{$\begin{array}{l}\text { Rotating } \\
\text { Biological } \\
\text { Contactor }\end{array}$} & $15 \leq Q \leq 1000 \mathrm{~m}^{3} / \mathrm{d}$ & 11,556 & 1.048 & 0.0005 & 0.9903 \\
\hline & $1000<Q<1500 \mathrm{~m}^{3} / \mathrm{d}$ & 16,062 & 0.282 & - & 0.9993 \\
\hline & $1500<Q \leq 1800 \mathrm{~m}^{3} / \mathrm{d}$ & 182.57 & 1.0783 & - & 0.9999 \\
\hline & $1800<Q \leq 30000 \mathrm{~m}^{3} / \mathrm{d}$ & 17,631 & 0.1863 & - & 0.9374 \\
\hline \multicolumn{2}{|c|}{ Compact Sequential Batch Reactor } & $9,842.1$ & 32.344 & & 0.9999 \\
\hline \multicolumn{2}{|c|}{ Waste Stabilization Ponds } & 293.2 & 0.3209 & & 0.9319 \\
\hline \multicolumn{2}{|c|}{ Constructed Wetlands-Lagoon } & 293.2 & 0.3209 & & 0.9319 \\
\hline \multicolumn{2}{|c|}{ Constructed Wetlands-Chlorination } & $9,733.2$ & 0.3209 & & 0.9319 \\
\hline
\end{tabular}

${ }^{*} \mathrm{~A}$ function of the form $\mathrm{K}_{\mathrm{p}}=\mathrm{a}+\mathrm{bQ}-\mathrm{cQ}^{2}$ provides better results

Similarly, Tables 7 and 8 summarize construction cost per Equivalent Population and the annual operating and maintenance cost per Equivalent Population respectively. Positive scale economies are observed also for Construction and O\&M cost. The trend is more evident for capacities up to 5,000 E.P. 
Table 6. Total Cost per Equivalent Population

\begin{tabular}{|c|c|c|c|c|c|}
\hline \multirow[b]{2}{*}{ Process } & \multicolumn{5}{|c|}{ Present Value Cost per E.P. (€/E.P.) } \\
\hline & $10^{2}$ & $10^{3}$ & $5 \times 10^{3}$ & $10^{4}$ & $2 \times 10^{4}$ \\
\hline Oxidation Ditch & 14,300 & 1950 & 598 & 390 & 281 \\
\hline Trickling Filter & 13,900 & 1900 & 582 & 381 & 268.5 \\
\hline Rotating Biological Contactor & 13,900 & 1820 & 530 & 397 & 270 \\
\hline Compact Sequential Batch Reactor & 6,394 & 1024 & 460 & 387 & 349.5 \\
\hline Waste Stabilization Ponds & 6,010 & 1010 & 366 & 255 & 187 \\
\hline Constructed Wetlands-Lagoon & 4,107 & 729 & 351.5 & 300.5 & 267 \\
\hline Constructed Wetlands-Chlorination & 5,905 & 975.5 & 434 & 335.5 & 290 \\
\hline
\end{tabular}

Table 7. Construction Cost per Equivalent Population

\begin{tabular}{|c|c|c|c|c|c|}
\hline \multirow[b]{2}{*}{ Process } & \multicolumn{5}{|c|}{ Construction Cost per E.P. (€/E.P.) } \\
\hline & $10^{2}$ & $10^{3}$ & $5 \times 10^{3}$ & $10^{4}$ & $2 \times 10^{4}$ \\
\hline Oxidation Ditch & 7049 & 1039 & 361 & 248 & 186.5 \\
\hline Trickling Filter & 6939 & 1049 & 379 & 267 & 201 \\
\hline Rotating Biological Contactor & 6289 & 891 & 309 & 258 & 187 \\
\hline Compact Sequential Batch Reactor & 2174 & 403 & 228 & 210 & 202 \\
\hline Waste Stabilization Ponds & 1742.5 & 428.5 & 216.5 & 168.5 & 136.5 \\
\hline Constructed Wetlands-Lagoon & 1031 & 324.5 & 250 & 243.5 & 235 \\
\hline Constructed Wetlands-Chlorination & 1827 & 463 & 302.5 & 260 & 245.5 \\
\hline
\end{tabular}

Table 8. Annual Operation and Maintenance Cost per Equivalent Population

\begin{tabular}{|c|c|c|c|c|c|}
\hline \multirow[b]{2}{*}{ Process } & \multicolumn{5}{|c|}{ Annual O\&M Cost per E.P. (€/E.P.) } \\
\hline & $10^{2}$ & $10^{3}$ & $5 \times 10^{3}$ & $10^{4}$ & $2 \times 10^{4}$ \\
\hline Oxidation Ditch & 419.58 & 55.90 & 16.10 & 10.21 & 7.03 \\
\hline Trickling Filter & 415.04 & 52.89 & 13.75 & 8.19 & 5.11 \\
\hline Rotating Biological Contactor & 392.95 & 48.75 & 12.31 & 7.79 & 4.85 \\
\hline Compact Sequential Batch Reactor & 346.61 & 48.17 & 15.81 & 11.13 & 8.56 \\
\hline Waste Stabilization Ponds & 231.42 & 31.21 & 8.41 & 4.97 & 2.96 \\
\hline Constructed Wetlands-Lagoon & 258.10 & 33.99 & 8.50 & 4.78 & 2.70 \\
\hline Constructed Wetlands-Chlorination & 342.00 & 43.00 & 11.01 & 6.32 & 3.75 \\
\hline
\end{tabular}

\subsection{Cost evaluation}

Waste Stabilization Ponds have the lowest annual maintenance cost followed by the other two natural wastewater treatment systems, the Constructed Wetlands with Lagoon or Chlorination. The Trickling Filter option has the highest annual maintenance cost. Figure 1 depicts the annual maintenance cost of all the studied systems for E.P. up to 20,000.

Energy consumption of Waste Stabilization Ponds and Constructed Wetlands with a Lagoon is minimal. When Chlorination is used for disinfection energy consumption rises substantially. Still though, the conventional wastewater treatment methods are more energy consuming than natural ones, with the Rotating Sequential Batch Reactor being the most energy consuming treatment system. Trickling Filters are 5\% more energy demanding than Constructed Wetlands with Chlorination, Rotating Biological Contractors require $15 \%$ more energy and Oxidation Ditches need 65\% more, whereas Compact Sequential Batch Reactors consume $55 \%$ more energy compared to Oxidation Ditches The energy consumption of the studied wastewater treatment methods for different flow rates is presented on Table 9. 


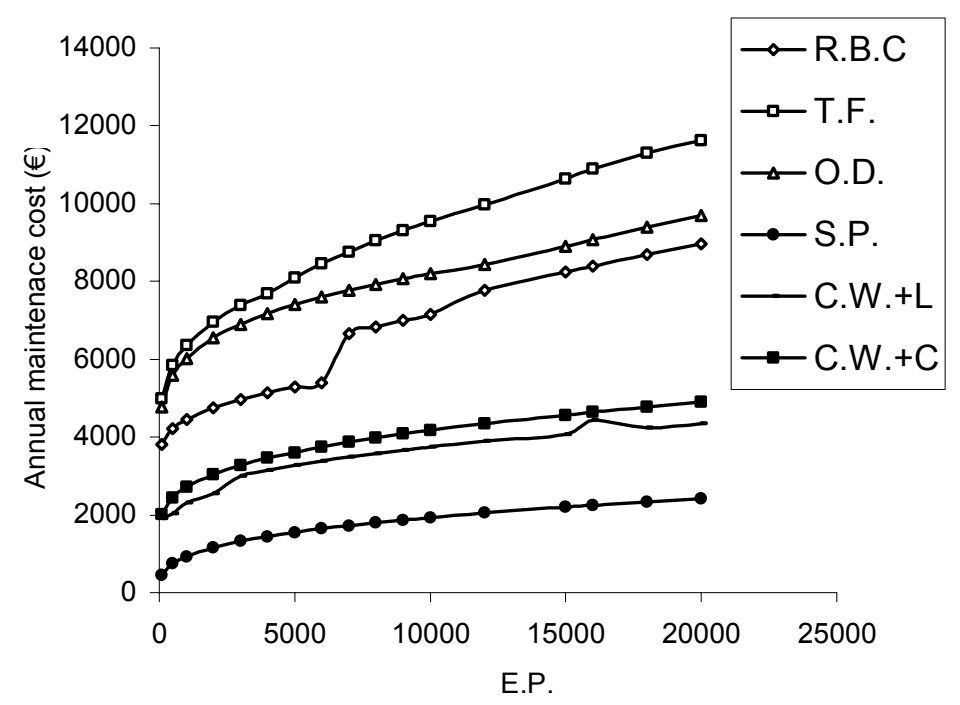

Figure 1. Annual maintenance cost of the studied wastewater treatment methods for different plant capacities

Table 9. Energy consumption for different wastewater treatment methods

\begin{tabular}{lcccccc}
\hline \multirow{2}{*}{ Process } & \multirow{2}{*}{ flow rate $\left(\mathbf{m}^{\mathbf{3}} \mathbf{d}^{-\mathbf{1}}\right)$} & \multicolumn{5}{c}{ Energy consumption (KWh) } \\
\cline { 2 - 6 } & $\mathbf{1 5}$ & $\mathbf{1 5 0}$ & $\mathbf{7 5 0}$ & $\mathbf{1 5 0 0}$ & $\mathbf{3 0 0 0}$ \\
\hline Oxidation Ditch & 1291 & 1527 & 2508 & 3709 & 6061 \\
Trickling Filter & 1269 & 1309 & 1420 & 1537 & 1754 \\
Rotating Biological Contactor & 1442 & 1466 & 1506 & 2060 & 2275 \\
Compact Sequential Batch Reactor & 1250 & 1863 & 4265 & 7288 & 13325 \\
Waste Stabilization Ponds & 12 & 36 & 76 & 104 & 144 \\
Constructed Wetlands-Lagoon & 12 & 36 & 76 & 104 & 144 \\
Constructed Wetlands-Chlorination & 1193 & 1216 & 1256 & 1284 & 1324 \\
\hline
\end{tabular}

The total cost of treatment plants involves costs for construction, salaries, energy, maintenance and chemicals; the latter not applicable in natural treatment plants. Among these components of the total cost construction cost stands out followed by salary costs. Gratziou et al. (2005) report that for conventional systems construction, salaries, energy, maintenance and chemicals expenses contribute to the total cost by $55 \%, 23 \%, 16 \%, 5 \%$ and $1 \%$ respectively, whereas for natural systems the aforementioned total cost components amount for $63 \%, 35 \%, 0.4 \%, 1.6 \%$ and $0 \%$ (i.e. no chemicals) respectively [8]. Analyzing total cost results, it can be highlighted that an increase in capacity corresponds to a decrease in cost per $\mathrm{m}^{3}$ of sewage or per E.P. Sewage treatment using natural methods is in every case the least expensive option. Table 10 presents a classification of the wastewater treatment methods (from the cheapest one to the most expensive one) for different plant capacities.

Table 10. Wastewater treatment methods classification according to total cost (from the lowest to the highest) for different plant capacities

\begin{tabular}{|c|c|c|c|c|c|}
\hline$\leq 10^{3}$ & $10^{3}-5 \times 10^{3}$ & $5 \times 10^{3}-8 \times 10^{3}$ & $\begin{array}{l}\text { E.P. } \\
8 \times 10^{3}-14 \times 10^{3}\end{array}$ & $14 \times 10^{3}-16 \times 10^{3}$ & $16 \times 10^{3}-2 \times 10^{4}$ \\
\hline C.W-L & C.W.-L & S.P. & S.P. & S.P. & S.P. \\
\hline C.W.-C & S.P. & C.W-L & C.W-L & C.W-L & C.W-L \\
\hline S.P. & C.W.-C & C.W-C & C.W-C & T.F & T.F \\
\hline S.B.R. & S.B.R. & S.B.R. & T.F & C.W-C & R.B.C. \\
\hline R.B.C & R.B.C. & T.F. & O.D. & O.D. & O.D. \\
\hline T.F. & T.F. & O.D. & R.B.C. & R.B.C. & C.W-C \\
\hline O.D. & O.D & R.B.C. & S.B.R. & S.B.R. & S.B.R \\
\hline
\end{tabular}


For capacities up to 5,000 E.P., the least expensive option is the Constructed Wetland with a Lagoon. If disinfection is achieved by chlorination, total cost rises by $33.7 \%$, construction cost by $43 \%$ and the annual O\&M cost by $28 \%$. Total cost rises by $28 \%$ if a Waste Stabilization Ponds system is chosen. The Compact S.B.R. method increases total cost by around $40 \%$, while construction cost is almost double for capacities up to 2,000 E.P.; for greater capacities no significant differences are observed. The R.B.C. systems total cost is double, while for capacities up to 2,000 E.P. the cost is actually three-times greater. Additionally construction cost triples but the O\&M cost is slightly reduced for R.B.C. In the Trickling Filter method, total cost is 2.5 times greater than the Constructed Wetlands- Lagoon system. Oxidation Ditch is the most expensive option for these capacities, its total cost being 2.5 times greater and construction cost triple.

For capacities over 5,000 E.P. and up to 20,000 E.P., Stabilization Ponds are found to be the least expensive option, followed by the Constructed Wetlands-Lagoon systems which increase total cost by $10-20 \%$ depending on plant capacity. Construction cost increases from $30 \%$ up to $60 \%$, while O\&M cost is reduced by $5 \%$ in comparison to Stabilization Ponds. When Chlorination is used as disinfection, construction cost rises by $7 \%$ and the annual O\&M cost by $34 \%$. There is actually a $12 \%$ increase in the total cost of the unit. The use of Trickling Filters results in a $45-55 \%$ increase of the total cost, a $40-60 \%$ increase of the construction cost and a $67 \%$ increase of the O\&M cost. Oxidation Ditch raises total cost by $50-60 \%$, construction cost by $30-55 \%$ and doubles O\&M cost. The Rotating Biological Contactor treatment increases total cost by $45-65 \%$, construction cost by $30-60 \%$ and O\&M by almost $60 \%$. For capacities between 8,000 and 20,000 E.P. the Compact Sequential Batch Reactor treatment is the most expensive option. Total cost is between 50 and $85 \%$ higher, construction cost between $20-40 \%$ higher and O\&M cost is 2.5 times greater.

\section{CONCLUSIONS}

The procedure used in the paper is based on the rationale that the wastewater processing system with the lowest cost still has to meet the legal specifications for water quality instead of dictating them, and should not be mixed with financial optimization terms that refer to production yield maximization and cost minimization.

The presented methodology provides a first detailed level for general planning and a technique for quick financial evaluation of the sewage treatment systems.

The derived cost equations can be used to feed multicriteria analysis of wastewater treatment processes.

Other parameters, such as land characteristics of the terrain, affect the cost of natural systems while conventional systems are not affected by them. For natural systems construction cost rises almost by $10 \%$ for every $1 \%$ increase in terrain slope and between $3-$ $7 \%$ for every $10 \%$ increase in rock percentage during excavations. An increase in land cost of $1000 €$ per $1000 \mathrm{~m}^{2}$ has a minimal effect on conventional systems but raises total cost by $1.2 \%$ for natural ones.

Sewage processing units using natural methods are in every case the least expensive option, especially when small E.P. are served. For E.P. up to 5,000 Constructed Wetlands with a Lagoon are the option with the lowest Total Cost whereas for E.P. greater than 5,000 and up to 20,000 Waste Stabilization Ponds represent the least expensive option.

Positive scale economies are observed; they are very strong for capacities up to 5,000 E.P., more so for the conventional systems.

\section{REFERENCES}

1. Kotsovinos N., Gratziou M. and Tsalkatidou M. (2005) Cost analysis and evaluation of conventional urban sewage processing units. In: Proceedings of the $3^{\text {rd }}$ International Conference on Ecological Protection of the Planet Earth, Istanbul.

2. EEC (1991) EEC/91/271 European Community's Urban Wastewater Treatment Directive, Official J. Eur. Communities, L135/40.

3. Andreadakis A. and Chalkia A. (1992) Cost accounting of Sewage Treatment Plants through Statistical Analysis of Data in Greece. In: Greek Hydrotechnic Union, Proceedings from the $5^{\text {th }}$ National Conference, Larissa. (In Greek) 
4. Gratziou M. (1998) Functions for Evaluating Urban Sewage Processing Cost, PhD Thesis, Department of Civil Engineering, Democritus University of Thrace. (In Greek)

5. Metcalf and Eddy Inc. (1995) Water Pollution Abatement Technology: Capabilities and Costs, Public Owned Treatment Works, Springfield, VA.

6. Gratziou M., (2002) Analysis of Wastewater Treatment Plant Cost. In: European Water Resources Management Association, Proceedings of the $5^{\text {th }}$ International Conference on Water Resources Management in the ERA of Transition, September, Athens, 529-537.

7. Economou S. (2003) Analysis of the Operating and Maintenance Costs for Urban Sewage Processing Units, M.Sc. Thesis, Department of Civil Engineering, Democritus University of Thrace. (In Greek)

8. Gratziou M., Ekonomou S. and Tsalkatidou M. (2005) Cost analysis and Evaluation of Urban Sewage Processing Units. In: K. P. Tsagarakis (ed.) International Conference on Water Economics, Statistics and Finance, Conference Reprint Book 1, 8-10, Rethymno, 417-424. 